\title{
Oficinas terapêuticas com mulheres velhas: um recorte de gênero, raça e classe
}

\author{
Therapeutic workshops with old women: a \\ gender, race and class approach
}

\author{
Karen Monteiro Aurelino dos Santos ${ }^{1}$ (1) \\ Kátia Jane Chaves Bernardo² (1) \\ Luisa Barros Santos de Araújo $^{3}$ (1)
}

1Autora para correspondência. Universidade do Estado da Bahia (Salvador). Bahia, Brasil. karenmonteiroas@gmail.com
2-3Universidade do Estado da Bahia (Salvador). Bahia, Brasil. katiajanebernardo@gmail.com, araujo.b.luisa@gmail.com

\begin{abstract}
RESUMO | A velhice, apesar de ser um fenômeno biológico, é perpassada por inúmeras questões sociais que incluem marcadores de gênero, raça e classe. Tal fator traz consequências como o processo de feminização da velhice, que indica o número maior de mulheres velhas em relação ao número de homens velhos. Além disso, há mais idosas brancas do que negras e indígenas em nosso país, devido a uma menor taxa de expectativa de vida desses grupos racializados. Desse modo, torna-se importante trabalhar com sujeitos velhos, levando em conta o contexto social onde esses estão inseridos. Nesse sentido, surge o projeto "Oficinas Terapêuticas com Mulheres Velhas", na tentativa de trabalhar fatores de vulnerabilidade específicos desse público, incluindo os entrelaçamentos de raça e classe. Tal projeto foi criado por duas estudantes do curso de Psicologia, e foi realizado na Universidade Aberta à Terceira Idade (UATI), no ano de 2019. O estudo teve como base a Psicologia dos Grupos, e tem como objetivo geral, a busca por reflexões acerca do fenômeno do envelhecimento da mulher e suas particularidades, considerando as variantes de gênero, raça e classe; para isso, alguns temas como relacionamentos conjugais, racismo, medo da morte e autoestima serão discutidos, a partir de um relato de experiência feito pelas estudantes estagiárias.
\end{abstract}

PALAVRAS-CHAVE: Mulheres. Velhice. Gênero. Raça.

\begin{abstract}
Despite being a biological phenomenon, old age is permeated by numerous social issues that include markers of gender, race, and class. This aspect has consequences such as the process of feminization of old age, which indicates the higher number of older women concerning the number of older men; in addition, there are more white elderly women than black and indigenous older women in our country, due to a lower rate of life expectancy of these racialized. As such, it is important to work with these groups, considering the social context where they are inserted; in this sense, the project "Therapeutic Workshops with Old Women" appears, in an attempt to work on specific vulnerability factors of this public, including aspects of race and class. Two students of a Psychology course have created this project and was carried out at the University Open to the Third Age (UATI) in 2019. To this end, the process of creating therapeutic workshops, in their needs and possibilities, was studied, always searching to creating a project suitable for space and its participants. The study was based on Group Psychology and had as its general objective, the search for reflections about the phenomenon of the aging of women and their particularities, considering the variants of gender, race, and class; for this, some themes such as marital relationships, racism, fear of death and self-esteem will be discussed, based on an experience report made by the intern students.
\end{abstract}

KEYWORDS: Women. Old age. Gender. Race. 


\section{Introdução}

No contexto brasileiro, termo "idoso" foi cunhado a partir da Constituição Federal de 1988, ao estabelecer a responsabilidade do Estado de proteger e assistir esse segmento populacional. O idoso é um ator político marcado, especialmente, a partir da idade cronológica - incluindo pessoas de 60 anos, independentemente do gênero, raça, crenças ou outras características (Lima \& Bueno, 2009).

De acordo Lima e Bueno (2009), a partir das décadas de 1940 e 1960, as transformações sociais e econômicas que ocorreram no Brasil levaram a uma aceleração do processo de envelhecimento populacional. Tal fato indica um aumento da expectativa de vida e, por consequência, um aumento no número de idosos no país. Isso pode ser relacionado, de um modo geral, à diminuição da taxa de mortalidade, como também da taxa de natalidade no país. Porém, o aumento no número de idosos se deu de forma rápida e progressiva exigindo do Estado novas iniciativas para dar conta das demandas do novo formato populacional do país, o que inclui, por exemplo, o aumento do uso, por sujeitos acima de 60 anos, do Sistema Universal de Saúde (SUS). De acordo com a Projeção da População do Instituto Brasileiro de Geografia e Estatística - IBGE (2018), o Brasil tem mais de 28 milhões de pessoas idosas, ou seja, $13 \%$ da população do país é composto por esse grupo etário, com uma tendência a dobrar nas próximas décadas, representando, em 2043, um quarto da população (IBGE, 2019).

Nesse sentido, é importante apontar que o processo de envelhecimento da população é marcado por uma feminização da velhice, o que significa que o número de mulheres velhas é significativamente superior ao número de homens velhos. Isso porque a velhice, além de se constituir como fenômeno biológico, é perpassada por inúmeros marcadores sociais que envolvem fatores de gênero, raça e classe. Para exemplificar, Lima e Bueno (2009) trazem dados apontados pelo IBGE, no ano de 2014, que apontam uma "sobremortalidade masculina", o que, por sua vez, leva a um processo de feminização da velhice. Além disso, para justificar tal processo, as autoras trazem dados apresentados por Chaimowicz (2006), que apontam a maior exposição masculina a acidentes de trabalho e de trânsito, bem como o maior uso de drogas por este grupo.
Apesar do aumento do número de idosos ter acontecido para todos os grupos raciais do Brasil, este apresenta algumas oscilações. Nesse sentido, é importante ressaltar que há, atualmente, uma maior expectativa de vida para brancos, do que para negros ou pardos no Brasil. O mesmo acontece com relação às idosas negras que sobrevivem em menor proporção com relação às idosas brancas (Silva et al., 2019). Isso se deve às altas taxas de homicídio e feminicídio contra a população negra (Senado Federal, 2018), além do menor acesso à educação, saneamento básico, alimentação adequada e serviços de saúde pela população negra (Menezes, 2018).

Com relação aos povos indígenas do Brasil, aponta-se uma subnotificação e faltas de dados para uma análise apurada das taxas de natalidade, mortalidade e expectativa de vida. Um levantamento de dados, realizado com base no Censo Demográfico de 2010, apontou que as taxas de mortalidade são maiores entre os indígenas - especialmente entre as mulheres -, do que entre os não-indígenas - o que afeta diretamente a expectativa de vida desses sujeitos, levando a uma redução do número de idosos; além disso, esse grupo populacional apresenta, em sua maioria, indicadores de saúde e socioeconômicos menos favoráveis que grupos não-indígenas (Campos et al., 2017). Desse modo, aponta-se que, por consequência de inúmeros indicadores sociais, a velhice ganha contornos que trazem especificidades aos profissionais que buscam atuar com essa parcela da população, sendo importante investigar os aspectos do público que será trabalhado.

Ao se referir às mulheres idosas brasileiras, Lima, \& Bueno (2009) afirmam que elas são, de modo geral, afetadas diferentemente dos homens pelo envelhecimento, sendo mais suscetíveis a problemas de saúde, como também ao isolamento social e transtornos emocionais relacionados à aposentadoria, perda de autonomia e viuvez. As mulheres, de acordo com pesquisas trazidas por Lima e Bueno (2009), apresentam maior fragilidade e perda de autonomia (Paz et al., 2006), vivendo com doenças crônicas por mais anos do que os homens (Chaimowicz, 2006) e $41 \%$ delas vivem sozinhas ou continuam viúvas, o que pode levar a um maior sentimento de solidão e abandono (Camarano, 2006). A isso, adiciona-se que essa camada tem maior probabilidade de ficar em uma situação socioeconômica desvantajosa e também são maioria em instituições de longa permanência (Lima \& Bueno, 2009). 
Além dessas questões, Salgado (2002) ainda aponta que as idosas se relacionam com a própria imagem de uma maneira negativa e depreciativa. Isso se dá devido à existência de crenças sociais sexistas, racistas e gerofóbicas que refletem a valorização da produtividade capitalista e do atrativo jovem físico e sexual. Tal fator culmina numa desvalorização social, que pode ser vista, por exemplo, na subrepresentação de mulheres velhas nos recursos midiáticos (Lesnoff-Caravaglia, 1984 citado por Salgado, 2002), especialmente quando não-brancas. Por consequência, essa constituição social leva a uma negação da velhice por mulheres, baixa autoestima e repressão sexual. Isso porque as rugas e os cabelos brancos, por exemplo, são associadas a um momento de decadência, e a entrada na menopausa diminui o prestígio de um corpo que é valorizado somente enquanto veículo reprodutivo e objeto sexual (Salgado, 2002).

A partir dos pontos levantados, indica-se a importância de um espaço específico para discussões acerca do envelhecimento feminino, em suas potencialidades e desafios, na busca pela promoção de uma melhor qualidade de vida para mulheres velhas - levando em considerações marcadores de gênero, raça e classe. Apesar dos avanços alcançados com relação aos direitos das mulheres nos últimos anos há, ainda, inúmeros fatores de vulnerabilidade e ações de violência para domesticação dos seus corpos e ações; tal fato indica a necessidade de ações e políticas voltadas especificamente para essa parcela da população. Desse modo, surge o projeto de estágio "Oficinas Terapêuticas com Mulheres Velhas", realizado em uma Universidade Aberta à Terceira Idade (UATI), com a proposta de ser um espaço de trocas apenas entre mulheres, para discussão de questões específicas ao envelhecer dessa população.

É importante destacar que o trabalho realizado na UATI é o de oficinas terapêuticas, que se diferenciam dos grupos terapêuticos. De acordo com Barros (2001), citado por Jucá et al. (2010), os grupos terapêuticos são usualmente vistos como espaços de escuta clínica e formação de vínculos afetivos, diferente das oficinas que aparecem como um lugar de reabilitação, tanto para a inserção no mercado de trabalho quanto para a socialização dos participantes. As oficinas seriam um espaço híbrido, onde a intervenção acontece no campo clínico e também no social, afirmam Jucá et al. (2010).

\section{Método}

Trata-se de um estudo de natureza qualitativa, descritiva, interpretativa e compreensiva de experiência em campo de estágio profissionalizante do curso de Psicologia, cujo objetivo principal é apresentar o desenvolvimento de oficinas terapêuticas com mulheres idosas matriculadas na UATI.

O relato de experiência, importante narrativa científica na pós-modernidade, permite a articulação entre teoria e prática, possibilitando a construção de saberes referentes à experiência em si, a partir da perspectiva do pesquisador em determinado contexto social, cultural e histórico, sem se constituir como uma obra fechada, e sim como a possibilidade de abrir a perspectiva da busca de novos saberes (Daltro \& Faria, 2019).

A base metodológica utilizada na atividade foi o trabalho com grupos. Yalom (2006) ao falar sobre a atuação da Psicologia dos Grupos, traz uma série de fatores terapêuticos que atuam como parte de um processo dinâmico vivido pelos participantes de um grupo a exemplo de transmissão de esperança, universalidade, compartilhamento de informações, altruísmo, recapitulação corretiva do grupo familiar primário, desenvolvimento de técnicas de socialização, comportamento imitativo, coesão, catarse e fatores existenciais. $\mathrm{O}$ autor também destaca a importância do papel do terapeuta na criação - o que envolve a escolha do local, a duração e a frequência das reuniões e a seleção de pacientes - e da manutenção do grupo.

Já de acordo com Ministério da Saúde (2004), as oficinas terapêuticas são atividades feitas em grupo e ministradas por um ou mais profissionais, monitores ou estagiários de diversas áreas. Sobre as atividades realizadas dentro de uma oficina terapêutica:

"[...] podem ser definidas através do interesse dos usuários, das possibilidades dos técnicos do serviço, das necessidades, tendo em vista a maior integração social e familiar, a manifestação de sentimentos e problemas, o desenvolvimento de habilidades corporais, a realização de atividades produtivas, o exercício coletivo da cidadania" (Brasil, 2004, p. 20). 
As oficinas também podem ser classificadas, ainda de acordo com o Ministério da Saúde (2004), em expressivas, que oferecem espaço de expressão plástica, corporal, verbal, musical, fotografia e teatro; geradoras de renda, que utilizam o aprendizado de uma atividade específica para a produção de renda; oficinas de alfabetização, que utilizam do exercício da escrita e da leitura como um recurso importante na reconstrução/construção da cidadania de usuários que não tiveram acesso ou não puderam permanecer na escola.

Este artigo tem como objetivos descrever a experiência de duas estudantes do curso de psicologia de uma instituição pública de Salvador/BA como facilitadoras das "Oficinas Terapêuticas com Mulheres Velhas" de uma Universidade Aberta à Terceira Idade; analisar temáticas trazidas pelas idosas durante a realização das oficinas, através da fala, escrita e de recursos artísticos como dança, música, colagens e massinha de modelar; e refletir sobre o fenômeno do envelhecimento da mulher e suas particularidades, considerando as variantes de gênero, raça e classe.

\section{Resultados e discussões}

A experiência de estágio que será aqui descrita foi desenvolvida no espaço da Universidade Aberta à Terceira Idade - UATI, programa de extensão universitária, que tem por finalidade propiciar aos idosos, oportunidades de exercício de suas capacidades artístico-culturais, dentro de um ambiente universitário.

O Núcleo Universidade Aberta à Terceira Idade (NUATI), vinculado à Pró-Reitoria de Extensão (PROEX), é formado por uma equipe multidisciplinar com profissionais da área de Psicologia, Pedagogia, Nutrição, Enfermagem, Biologia, Direito, entre outros, e atende idosos de ambos os sexos, de todos os níveis sócio educacionais, a partir dos sessenta anos de idade.

Tal projeto tem como objetivo principal a formação continuada desses sujeitos, a partir do acesso a atividades que incentivem a participação social, política, além de oportunizar a troca de experiências intergeracionais. Visa, ainda, a reinserção psicossocial desses idosos, por meio de ações educativas que levem a reflexões acerca das diversas concepções do envelhecimento no contexto contemporâneo (Nuati, 2013).
O programa atual é um desdobramento do que em 1995 chamava-se Grupo de Trabalho da Terceira Idade (GTTI), que atendia cerca de 60 idosos. Atualmente, a UATI apresenta como linhas de ação a educação continuada, atividades de cultura e lazer, além de oficinas (teóricas, corporais, manuais e de tecnologia e informação) que visam a orientação quanto a fatores físicos, psicológicos e sociais e produção de renda.

\section{Oficinas terapêuticas com mulheres velhas}

Apesar da presença de pessoa de ambos os sexos nas oficinas da UATI, as mulheres são a maioria. A partir de tal percepção, no ano de 2017, foi realizada uma pesquisa - desenvolvida pelas mesmas autoras do artigo, para a disciplina de Desenvolvimento III (Velhice) - sobre o entendimento que as idosas frequentadoras da UATI tinham sobre o conceito de empoderamento feminino e das opressões sexistas. Para Gonçalves (2014), tal conceito indica a conquista de autonomia em diversos seguimentos da vida da mulher, gerando impactos no que se refere ao controle dos seus corpos, de sua sexualidade, do seu direito de ir e vir, assim como a imposição dos seus desejos e vontades e o combate ao abuso físico e psicológico.

É só a partir da tomada de consciência acerca dos desafios e opressões impostas por uma sociedade sexista, que se pode pensar em romper com a lógica socialmente imposta. Tal processo usualmente começa a partir da percepção das próprias experiências, no entendimento de algumas delas como fontes de sofrimento e insatisfação. No caso das mulheres velhas, segundo Gonçalves (2014), o empoderamento também implica no rompimento com a lógica assistencialista dominante, na busca por relações de parceria, não-hierarquizadas.

A partir dessa pesquisa, realizada em 2017, foi percebida a vivência de situações de violência, opressão, dependência financeira e reprodução de conceitos e termos sexistas pelas idosas entrevistadas, o que indica necessidades específicas no cuidado da saúde física e mental de mulheres idosas. Desse modo, foi criado o projeto "Oficinas Terapêuticas com Mulheres Velhas", como experiência de estágio para alunas de Psicologia, a partir do oitavo semestre do curso. Este projeto surge como uma iniciativa estudantil para criação de um espaço exclusivo para discussão de 
questões relacionadas ao envelhecimento de mulheres, em seus desafios, dificuldades e possibilidades.

Para planejar uma oficina terapêutica deve-se considerar o funcionamento da instituição em que ela irá acontecer, e em que território esse espaço está localizado, levando em conta os seus aspectos culturais, locais e regionais. Aponta-se também para a necessidade de previamente definir o perfil do grupo a ser trabalhado e, a partir disso, conhecer, investigar e acolher as demandas desses sujeitos. Tal fator deve ser continuado ao longo dos encontros, a partir da inclusão da participação dos usuários tanto nas decisões tomadas pelo grupo, quanto no planejamento da oficina e dos encontros seguintes. Além disso, deve-se pensar no efeito terapêutico de cada oficina para cada participante, considerando também que apenas a convivência durante os encontros já pode trazer efeitos terapêuticos, mesmo que nem todos os membros participem ativamente do grupo (Nunes et al., 2015).

Como pré-requisito para a realização das oficinas terapêuticas com as idosas matriculadas na UATI, era necessária a participação das estagiárias em um grupo de estudos, coordenado pela professora orientadora do estágio, que antecedeu o início dos encontros, cujo objetivo era subsidiar teoricamente as estudantes para o trabalho a ser desenvolvido. A partir do entendimento do funcionamento das oficinas terapêuticas, as estagiárias responsáveis pelo grupo terapêutico com as mulheres idosas escreveram um projeto cujos objetivos principais eram a criação de um espaço de reflexão orientada sobre o fenômeno do envelhecimento da mulher e suas particularidades e a promoção de discussões orientadas sobre desigualdades de gênero, raça e classe, e suas consequências.

O projeto foi estruturado em quatro blocos: o primeiro bloco tinha como foco o papel da mulher na sociedade, o segundo foi relacionado a questões sobre sexualidade e corpo; em seguida, foram trabalhados pontos relacionados a redes de apoio e, por fim, qualidade e trajetória de vida. É interessante ressaltar que tal divisão foi didática, mas todas essas questões principais permearam toda a trajetória do grupo. Além disso, a base do planejamento era mantida, mas os encontros eram elaborados semanalmente, a partir das discussões surgidas no encontro anterior.
Os encontros eram conduzidos por duas estudantes do curso de Psicologia, matriculadas no Estágio Supervisionado, no ano de 2019, entre os meses de agosto e dezembro, sob a supervisão de uma professora responsável. Os encontros foram realizados semanalmente, com duração de 1 hora e 30 minutos. Ao todo, foram realizados 23 encontros. O grupo contou com 8 participantes, entre 60 e 80 anos de idade, onde cinco eram casadas, uma era viúva, uma era divorciada e uma era solteira.

Foi estabelecido um contrato entre todas as participantes do grupo, envolvendo tópicos discutidos em grupo, tal qual o horário de chegada, a importância do sigilo das informações partilhadas e o cuidado no julgamento pessoal da fala das outras participantes. Esse contrato inicial demarca os padrões grupais, que são as expectativas das participantes com relação aos membros do grupo. A clareza nas normas e combinados facilita a expressão de comportamentos e atitudes desejáveis fortalecem a coesão entre os membros do grupo garantindo o sentimento de confiança na eficácia do modelo de grupo, fator fundamental no processo grupal.

Os recursos utilizados nas atividades realizadas durante as oficinas podem ser terapêuticos ou não, dependendo do uso técnico que se faz deles. Esses recursos podem ser a fala, o corpo, colagem, imagens, pintura, massa de modelar (Nunes et al., 2015). Nesse sentido, é importante levar em conta as possibilidades materiais do espaço, a receptividade dos sujeitos às práticas oferecidas e a disponibilidade dos materiais. No grupo terapêutico com as idosas, criou-se um espaço de escuta e troca, onde as participantes podiam compartilhar suas vivências, utilizando-se de variadas dinâmicas e recursos artísticos, além de encontros com convidados externos que realizaram novas dinâmicas e discussão de temáticas relacionadas a outras áreas, que não apenas a Psicologia - como exemplo, uma médica foi convidada para a discussão das mudanças físicas e biológicas relacionadas à velhice.

Durante os 23 encontros com as participantes foram realizadas atividades manuais e corporais, com o uso de recursos sonoros e visuais para abertura das trocas acerca da temática do encontro. Usualmente, as estudantes levavam músicas ou textos para abertura da temática e chegadas das idosas. Após esse momento, a dinâmica do dia era explicada e os recursos 
eram distribuídos; tais dinâmicas envolveram momentos individuais e momentos em duplas e trios. Com a conclusão da produção do dia pelas idosas, o grupo completo era novamente reunido para discussão daquilo que foi produzido e percebido. Inúmeras questões foram trabalhadas tais como: medos relacionados à velhice, sexualidade e práticas sexuais na terceira idade, violência conjugal, divórcio, solidão, racismo, laços afetivos, autocuidado, autoestima e limitações físicas relacionadas ao envelhecimento.

Nas seções seguintes alguns dos temas mais mobilizadores e recorrentes durante os encontros, serão trabalhados e discutidos, a partir de um relato de experiência, tendo como base a teoria disponível e a experiência prática com as idosas.

\section{Racismo}

Em um dos encontros da Oficina Terapêutica para Mulheres, cuja temática versava sobre "Corpo e Sexualidade", foi trabalhada a importância do contato com o próprio corpo através do canto e da dança, na tentativa de aumentar a percepção de sensação, movimento pessoal e incentivar o autocuidado. Durante a atividade, as idosas foram convidadas a dançarem umas com as outras, muitas vezes através de toques e movimentos conjuntos.

A troca afetiva estabelecida entre as participantes trouxe como tema norteador para a discussão do grupo, o medo de sofrer racismo. Gonçalves (2014) afirma que existem mitos e teorias sobre a velhice e elas podem ou não ser verdadeiras, mas a maior "não-verdade" seria a de enxergar a velhice com características bem definidas e a vivência da velhice como homogênea. Nesse sentido, a vivência da muIher negra velha traz especificidades que não são vivenciadas por mulheres brancas. De acordo com Santos (2016), o envelhecimento da mulher negra pode representar a vivência de quatro discriminações: de gênero, raça, classe (já que um número alto pertence às camadas sociais mais pobres) e de idade. hooks ${ }^{1}$ (2019) afirma que fatores como classe, raça, religião, preferência sexual criam uma diversidade de experiências e que isso também determina de que maneira o sexismo afeta a vida dessas mulheres. A autora traz uma crítica à definição do feminismo como "um movimento cujo objetivo é as mulheres obterem a igualdade social relativamente aos homens", afirma hooks (2019, p. 14), já que as mulheres das classes mais baixas e mais especificamente as não brancas, não entendem a libertação das muIheres apenas como a busca por igualdade entre os gêneros; isso porque, nem todas as mulheres compartilham do mesmo estatuto social e, além disso, as mulheres negras assistem constantemente aos homens nos seus grupos sociais serem discriminados, explorados e oprimidos.

Desde o início do movimento pela libertação das mulheres, estas [as mulheres negras] suspeitavam do feminismo precisamente porque reconheciam as limitações intrínsecas na sua definição. Reconheciam a possibilidade de o feminismo, ao ser definido como igualdade social entre homens e mulheres, facilmente se tornar num movimento que afetaria primeiramente

a condição social das mulheres brancas da classe média e alta, afetando apenas de maneira muito superficial o estatuto social das mulheres pobres e da classe trabalhadora (hooks, 2019, p. 15).

hooks (2019) aponta para a necessidade de se repensar a teoria e o movimento feminista construído e pensado majoritariamente por mulheres brancas, de classe média e alta que estão inseridas em um ambiente acadêmico. Muitas dessas mulheres brancas conseguiram encontrar soluções para os seus dilemas pessoais dentro do movimento feminista e se negam a analisar e a criticar a sua estrutura e que tipo de influência o mesmo movimento gerou na vida de outras mulheres de realidades diferentes. Segundo hooks (2019), as mulheres brancas tomam como referência a sua própria narrativa individual e a consideram universal, não conseguindo compreender a interligação existente entre opressão de gênero, de raça e de classe, ou se recusam a levar esses aspectos a sério.

\footnotetext{
${ }^{1}$ A própria autora emprega o seu nome em letra minúscula como um posicionamento político, buscando dar enfoque ao seu trabalho e não à sua figura. Este artigo acata a escolha da autora.
} 
É fundamental encorajar as mulheres a desenvolverem um conhecimento profundo e abrangente de toda a realidade política, compreendendo também as diversas realidades sociais e políticas das mulheres, especialmente as que não têm sido pautas de obras, estudos ou de mudança por parte dos movimentos políticos. Com essa compreensão global das diferentes realidades, o movimento feminista deixa de focar na visão de que o homem é o inimigo e deslocamos o nosso olhar para o exame do sistema de domínio e do papel que cada um exerce na manutenção do mesmo (hooks, 2019).

Martins et al. (2018) realizaram um estudo com o objetivo de avaliar os impactos das microagressões raciais de gênero que incluem a marginalização, o silenciamento e a objetificação sobre a saúde mental de mulheres negras. As microagressões são "insultos verbais ou comportamentais, intencionais ou não, que comunicam ofensas raciais hostis, depreciativas ou negativas", explicam Martins et al. (2018, p. 2794). Os autores trazem exemplos de outros estudos que relatam, como a relação entre experiências de cunho racista com o uso abusivo de substâncias, a baixa autoestima, a transtornos mentais e a sintomas depressivos de modo geral. Uma das justificativas do trabalho é o fato de que pesquisas sobre racismo normalmente tratam os negros com um grupo único, desconsiderando as potenciais diferenças de gênero e, pode-se acrescentar, de geração.

O estudo de Martins et al. (2018) concluiu que a convivência com estressores ambientais crônicos, como a experiência da discriminação racial de gênero, indicam piores índices de saúde mental. Além disso, as frequências dessas microagressões também afetam negativamente a autoestima de mulheres negras, já que a ideia de autoestima também está associada à forma como o outro nos enxerga. Lidar com a discriminação e a desvalorização social de suas características físicas faz com que a pessoa internalize parcialmente essas opiniões. Nesse sentido, os autores destacam a importância de incorporar processos psicológicos gerais para buscar compreender a ligação entre discriminação e sofrimento psíquico de grupos socialmente marginalizados.
Pode-se afirmar, portanto, que o processo de enveIhecimento das mulheres negras é heterogêneo e atravessado por questões de gênero, raça, classe social, o que, de acordo com Santos (2016), pode reforçar desigualdades. A autora realizou entrevista com mulheres negras velhas e percebeu que, independente das experiências individuais de cada uma, o gênero, a raça e o fato de serem mães trabalhadoras com baixa escolaridade interferiram na sua construção enquanto sujeito social. Grande parte das experiências vividas por essas mulheres não havia a possibilidade de escolhas, mas sim obrigações a cumprir e necessidades a atender.

O Informe Brasil para III Conferência Regional Intergovernamental sobre Envelhecimento na América Latina e Caribe de 2012, observou um número crescente de mulheres negras chefiando lares, um maior envolvimento das mulheres negras em atividades domésticas, enfatizando as diferentes velhices vivenciadas por mulheres negras e pobres e pelas muIheres brancas e de classe média e alta. Observa-se, ainda, que há um número maior de velhas brancas que negras, o que seria justificado pela alta taxa mortalidade da população negra entre 15 e 29 anos, e a proporção da população negra pobre, idosa ou não, é mais elevada do que a branca, o que torna mais adversa as condições de vida da mulher negra idosa (Santos, 2016).

Foi possível observar os efeitos do sofrimento psíquico dessas mulheres no encontro citado anteriormente, cujo objetivo da dinâmica era formar um "corredor do abraço" - as participantes deveriam passar por esse corredor e receber abraços das demais, incluindo as estudantes que conduziam o encontro. A proposta inicial da oficina era promover o fortalecimento da rede de apoio que estava sendo construída entre as idosas através da troca afetiva, não estando previsto o tema do racismo. Após a intervenção, uma das participantes afirmou que, por ser negra, evitava abraçar as pessoas com medo de ser rejeitada. Fica claro que as marcas deixadas pelo racismo atingem as diversas experiências vividas pela mulher negra incluindo, aí, o contato corporal através do abraço. 
A "Oficina Terapêutica com Mulheres Velhas" é formada em sua maioria por mulheres negras velhas e se apresenta como um espaço de escuta e de acoIhimento para a demanda dessas mulheres. Os encontros são organizados previamente, mas sempre abrindo um espaço para as demandas e necessidades do grupo. Sendo assim, o surgimento de falas sobre o racismo e os impactos que a discriminação racial trouxe para a construção de vínculos e troca de afetos, exigiram uma postura acolhedora diante do que foi trazido, legitimando o discurso trazido e discutindo a criação de estratégias para lidar com a situação de modo individual e coletivo.

\section{Relações conjugais}

A discriminação sexista estabelece lugares específicos que devem ser ocupados pelas mulheres; porém, é importante relacionar a opressão de gênero com aspectos de raça e classe que se retroalimentam na tentativa de manter o sistema. Desse modo, por exemplo, Bassit (2004), citado por Gonçalves (2014), afirma que mulheres nascidas no Brasil entre os anos de 1920 e 1930 passaram por uma educação com base em valores familiares tradicionais, com o objetivo de prepará-las para o casamento - esse que era considerado o ápice da vida de uma mulher, juntamente com o nascimento dos seus filhos. Apesar disso aponta-se, por exemplo, a menor nupcialidade de mulheres negras e, por consequência, surgimento de sensações de solidão e abandono (Santos, 2016).

Além disso, de acordo com Lima e Bueno (2009) as idosas de hoje são, em sua maioria, aquelas que tiveram a família como referência principal e primordial e desempenharam durante toda a vida o papel de esposa e de mãe dentro dos espaços domésticos. Porém, a partir do século XIX inúmeras mudanças foram acontecendo no cenário da família brasileira, a partir da industrialização - o que permitiu às mulheres a ocupação de novos espaços e a formação de novas identidades. Apesar disso, é importante considerar que mulheres negras entraram no mercado de trabalho muito antes que as mulheres brancas, dando início à dupla jornada previamente - com o acúmulo do trabalho fora de casa e do trabalho doméstico -, em empregos subalternos e de baixa remuneração (hooks, 2019). Além disso, desde essa época, era mais comum a existência de uma mulher como chefe da família entre as famílias negras - do que entre as brancas. Nesse sentido, é importante enfatizar que o envelhecimento é um processo individual, mas também multideterminado, sendo importante levar em consideração os determinantes sociais.

Apesar disso, com a feminização da velhice, aponta-se a tendência de mulheres velhas viverem sozinhas ou continuarem viúvas (Camarano, 2006 citado por Lima, \& Bueno, 2009); em contradição, com relação ao projeto desenvolvido, mulheres casadas eram a maioria no projeto apresentado. Inicialmente, não foram relatadas situações problemáticas dentro das relações conjugais, o que foi de encontro a literatura pesquisada pelas estudantes; foi só a partir do maior envolvimento grupal e aumento da coesão, que muitas críticas direcionadas aos companheiros e a vida matrimonial começaram a aparecer durantes os encontros. Foi interessante perceber a maior dificuldade na percepção de violências dentro de uma relação matrimonial, supostamente estável e reforçada pelo grupo social - especialmente quando essa é feita por vias não-físicas. Assim, a escuta de vivências semeIhantes entre as idosas as incentivou na compreensão e no compartilhamento de certas situações de violência vivenciadas dentro de casa.

A partir disso, consideramos importante descrever os tipos de violência mais direcionados às mulheres no Brasil. Além da violência física que envolve chutes, socos e outras formas de agressão, há também a violência psicológica que inclui danos emocionais a partir de ofensas, humilhações, proibições ao lazer e ameaças, por exemplo. Tais ofensas, quando realizadas em ambientes públicos, são consideradas formas de violência moral, que levam a sentimentos de vergonha e/ou constrangimento. Há também a violência patrimonial que se relaciona à destruição de documentos e outros pertences importantes e/ou vendas de bens sem a concordância da vítima. Por fim, há a violência sexual que inclui assédios, práticas sexuais forçadas e divulgação de imagens e vídeos de conotação sexual sem o consentimento da vítima (Defensoria Pública do Estado da Bahia, 2015).

Além das dificuldades de entendimento das violências sofridas há, também, as dificuldades nas denúncias e na modificação dessas circunstâncias - inclusive porque muitas das idosas são financeiramente dependentes dos companheiros. No caso das oficinas apresentadas, apenas uma das idosas possuía 
maior independência financeira devido a uma formação em ensino superior; as outras participantes do grupo eram todas donas de casa que não possuíam renda própria - muitas delas sendo impedidas de trabalhar pelos companheiros. Desse modo, reforça-se a importância do espaço das oficinas terapêuticas para a identificação das ações de violência e criação de possíveis estratégias de enfrentamento, o que inclui ainda a divulgação de espaços para denúncia e suporte judicial, visto que a falta de informações se constitui como uma estratégia para perpetuação das estruturas de opressão e poder.

Ainda com relação à violência conjugal, ao longo das oficinas, foram também levantadas inúmeras violências sexuais sofridas por essas mulheres com a chegada do matrimônio. Tal fato foi muito associado às relações de poder desiguais de gênero, inclusive dentro dos ambientes domésticos, como também ao desconhecimento com relação ao próprio corpo e as atividades sexuais, incluindo os riscos envolvidos. De acordo com as idosas, as únicas informações passadas por médicos, ao longo da sua existência, foram voltadas para a prevenção de uma gravidez indesejada.

A falta de espaço para discussão das questões relacionadas à sexualidade - fato trazido nos encontros e também pela literatura - tem como uma de suas consequências diretas o aumento global dos números de ISTs em idosos, apontados em inúmeras publicações recentes. Segundo o Ministério da Saúde, por exemplo, entre 1998 e 2010, houve um aumento de $42 \%$ no número de idosos infectados pelo vírus HIV. Apesar do aumento do número de pesquisas, não se pode desconsiderar comportamentos de riscos praticados por esse grupo (Dornelas et al., 2015). Por exemplo, com a chegada da menopausa não há mais risco de gravidez o que, por sua vez, pode levar a recusa no uso de preservativos sexuais. Além disso, outros fatores são apontados para redução no uso de preservativos, que incluem ainda as dificuldades com o manuseio do preservativo e a suposta piora masculina no desempenho sexual.

Desse modo, além de fatores de risco biológicos pertinentes ao envelhecimento, tais como a diminuição da imunidade celular e a diminuição na lubrificação feminina, que pode facilitar a abertura de microfissuras e facilitar a transmissão das ISTs, existem inúmeros fatores sociais que permeiam tal questão. Como exemplo, ressalta-se que as desigualdades de classe e raça no país afetam diretamente a população que tem acesso ao acompanhamento médico e à realização de exames para detecção de problemas. Ademais, ainda que os idosos consigam acessar o sistema de saúde, aponta-se a falta de iniciativas médicas para discussão de estratégias de prevenção e tratamento relacionados às ISTs - especialmente quando as pacientes são mulheres (Dornelas et al., 2015). Além de tal problemática, a falta de informações afeta também o prazer alcançado por essas mulheres em suas práticas sexuais. De acordo com uma pesquisa feita por Penteado, Fonseca et al. (2004) com idosas, $35 \%$ atingia o orgasmo apenas esporadicamente com o parceiro e $35 \%$ delas nunca o alcançou em relações sexuais. De acordo com outra pesquisa trazida pelas autoras, e realizada por Laumann et al. (1999), quase 30\% das mulheres brasileiras afirmam terem dificuldades em alcançar orgasmos e atingir o ápice na relação sexual, essa que ainda é bastante voltada ao prazer masculino.

Para trabalhar a questão da sexualidade com as participantes da oficina, foi realizada uma dinâmica em que algumas frases eram lidas por uma das mediadoras e, de olhos fechados - para evitar grandes desconfortos -, as idosas que se identificavam tinham que levantar as mãos; as frases lidas relacionavam-se a práticas de auto estimulação sexual, prazer nas relações com terceiros e conhecimento acerca das ISTs. Em seguida foi aberta uma roda de conversa com as idosas que foram bastante receptivas, visto os relatos de falta de espaço para discussões acerca da temática. Nessa discussão surgiram temas como as dificuldades no uso de preservativos - por recusa do companheiro -, a falta de acompanhamento médico em virtude das mudanças físicas relacionadas à menopausa e sexualidade, e a falta de informações que as acompanhou ao longo da vida - relacionadas às ISTs, mas também a prevenção de gravidez indesejada. Consideramos que o encontro foi importante para o compartilhamento de histórias similares, o aumento dos vínculos grupais e a criação de estratégias de enfrentamento frente às dificuldades atuais relacionadas à temática. Além disso, foram também compartilhadas informações importantes com relação às ISTs e muitas idosas sentiram-se estimuladas a buscarem um acompanhamento médico adequado. 


\section{Autoestima e autoimagem}

Com relação ao corpo, temáticas relacionadas a autoestima foram bastante recorrentes, surgindo em múltiplos encontros. Durante conversas com o grupo ficou clara a ideia da existência de um padrão para se vestir e se comportar dentro da velhice, onde roupas mais curtas, biquínis e cabelos muito compridos, por exemplo, seriam inadequados. Além disso, a dificuldade em aceitar as mudanças vividas pelo corpo também apareceu como demanda.

De acordo com Duridan et al. (2014), a autoestima é um conjunto de sentimentos e pensamentos que o indivíduo constrói sobre si mesmo e que gera uma representação pessoal que pode ser positiva ou negativa (Hutz \& Zanon, 2011 citado em Duridan et al., 2014 , p. 175). As autoras ainda citam que uma autoestima elevada também implica a aceitação e o reconhecimento positivo dentro de um campo social e também de pessoas significativas para o indivíduo. Considerando o contexto de uma sociedade capitalista, machista e racista, a cobrança para caber em um padrão de beleza pré-estabelecido cresce quando se refere a mulheres velhas.

Para Santos e Maia (2013), citado em Duridan et al. (2014), essa cobrança está associada a fatores culturais, que valoriza imagens idealizadas de beleza física, principalmente para as mulheres, desconsiderando a passagem do tempo. De acordo com Fin (2014), a sociedade força as mulheres a serem responsáveis pela sua aparência, sendo este o seu dever moral. Ou seja, é obrigação da mulher estar sempre bonita, vestida adequadamente e apresentável para o outro, qualquer coisa que fuja desse padrão branco, jovem e magro carece de valor. As mulheres idosas de alto poder aquisitivo ainda conseguem ter acesso a procedimentos que a aproximem desse padrão, como cirurgias plásticas e o acompanhamento de profissionais como nutrólogos, personal trainners, entre outros. Mas isso é uma realidade distante para mulheres de classes mais baixas. Dessa maneira, segundo Fin (2014), a autopercepção do corpo envelhecido com sinais de enrugamento, encolhimento, descoloramento dos cabelos e menor agitação são encaradas com pesar.

Com o objetivo de desconstuir os mitos e preconceitos sobre a velhice, realizou-se, uma dinâmica em que as facilitadoras apresentaram imagens de muIheres em diversas fases da vida, em inúmeras profissões e com foco nas mais variadas partes do corpo.
A dinâmica foi dividida em dois momentos: no primeiro momento, as idosas deveriam pegar imagens de mulheres com as quais não se identificassem e, posteriormente, deveriam relatar para o grupo com qual imagem se identificavam. À partir daí foi possível conhecer e trabalhar as perspectivas positivas e/ou negativas que essas mulheres têm do próprio corpo, mas também das próprias capacidades emocionais ou relacionadas ao trabalho, por exemplo. As trocas com outras mulheres possibilitaram um processo de reconhecimento do próprio corpo, em potencialidades e fragilidades, muitas vezes compartilhadas por elas. Além disso, muitos dos pontos ressaltados como negativos, eram considerados como qualidades por outras mulheres, o que levava a uma valorização do que antes era diminuído.

Para discussão dos pontos levantados, foram utilizadas as ideias de Clarissa Pinkola Estés (1997) que, em seu livro "Mulheres que correm com os lobos", defende a ideia de um corpo que é meio para relação do sujeito com o mundo e receptáculo de experiências e lembranças que são parte da construção da nossa existência individual. Desse modo, para Estés (1997), o corpo tem como função primordial nos conectar com sensações e com o prazer, não apenas o sexual, mas também aquele que existe no calor ou no frio, no contato com os elementos na natureza, com diversas experiências sensoriais e com outros seres humanos, além de poder ser utilizado como meio para expressão através das inúmeras manifestações artísticas possíveis, como a dança ou o canto. A partir disso, a autora rompe com a ideia de relação com o corpo apenas a partir de uma busca por alcance de padrões corporais brancos, novos, magros e esguios ou como meio para obtenção de prazer por terceiros.

Deve-se também enxergar o cuidado com o corpo como um ritual de autocuidado para que a mulher velha se sinta confortável com o que ela vê no espeIho e não para forçar uma adaptação a um padrão que não corresponde com a realidade das mulheres velhas brasileiras. $O$ autocuidado não deve estar restrito apenas ao cuidado estético, o que tornaria sua vivência possível apenas para aquelas que tivessem condições financeiras de acessá-lo. Sua prática deve estar associada ao sentimento de bem-estar e deve ser pensada a partir da realidade de cada idosa. A veIhice deve ser enxergada como uma fase significativa que, apesar de contar com limitações, também carrega uma série de potencialidades assim como qualquer outra fase da vida. 


\section{Medos relacionados à velhice}

Outra temática bastante mobilizadora, envolveu a discussão dos medos relacionados à velhice. Para isso, solicitou-se que as idosas escrevessem seus maiores medos em um pedaço de papel que foi dobrado e depois exposto ao grupo - sem, obrigatoriamente, revelar a identidade da autora, para que estas se sentissem mais confortáveis com a exposição. Ademais, as trocas com o grupo foram importantes para a percepção das semelhanças entre elas e, consequentemente, fortalecimento dos vínculos do grupo.

Além do medo da solidão, outros medos se destacaram, tais como: medo do desconhecido após a morte, medo de doenças associadas à terceira idade, especialmente a doença de Alzheimer, o medo da falta de apoio familiar e da estadia em abrigos. A partir das exposições dos medos para o grupo, a tarefa proposta foi pautada na construção de estratégias de enfrentamento, sendo inúmeras possibilidades levantadas e discutidas pelas participantes.

Nesse momento, torna-se importante ressaltar que a UATI, espaço gratuito para realização de oficinas com idosos, foi unanimemente trazida como um espaço insubstituível para a manutenção da qualidade de vida de seus participantes, ao contrário do que podemos encontrar em instituições de longa permanência. A gratuidade da experiência é um dos fatores mais importante para que muitos idosos possam acessar os serviços disponibilizados. No caso da oficina presente, a maioria das integrantes do grupo não possuía renda própria, sendo os gastos controlados exclusivamente pelo marido - muitos desses que não eram a favor da participação das mulheres nas oficinas. Aqui se levantam possibilidades para as restrições dos companheiros, que podem incluir o controle do ir e vir das esposas, o controle das relações extrafamiliares permitidas e a ausência delas em casa - que implica diretamente na reorganização dos serviços domésticos.

De acordo com a ANVISA, as Instituições de Longa Permanência (ILPIs) são instituições governamentais ou não-governamentais, voltadas para a residência de sujeitos com 60 anos ou mais, na condição de liberdade e cidadania; nesses locais residem sujeitos em situações de vulnerabilidade de renda, mas também aquelas com dificuldades na realização das atividades diárias. Apesar disso, esses espaços ainda são comumente chamados de "abrigos" ou "asilos", sendo usualmente associados apenas à atuação da assistência social e carecem de recursos e políticas públicas voltadas para a sua execução adequada (Camarano \& Kanso, 2010). Oliveira (2006) aponta a falta de preparo dos profissionais atuantes nesses espaços públicos, mas também nos espaços particulares - que ainda demandam custos elevados aos clientes. Esses fatores somados culminam numa queda brusca da qualidade de vida de idosos asilados.

Ademais, a solidão é apontada como uma das principais queixas trazidas por idosos residentes de ILPIs, na cidade de Salvador, na Bahia. A falta de visitas de familiares, as dificuldades na formação de vínculos além de uma baixa autoestima são fatores apontados pela autora para que tal situação se estabeleça - todos esses elementos que foram trazidos pelas idosas ao longo dos encontros. Muitos dos idosos entrevistados pela autora também evitam demonstrar a necessidade de companhia e atenção para seus parentes, por culpa e receio de gerar incômodos (Oliveira, 2006).

Além disso, a falta de liberdade e consequente privação do direito de ir e vir, também foi um elemento presente na pesquisa realizada, visto que os idosos são obrigados a seguirem as regras da instituição, que ditam horários de lazer, alimentação e restringem as suas saídas do espaço; devido a isso, os abrigos foram descritos como "prisões". Coadunando com isso, a autonomia foi um dos fatores mais levantados como pilar na qualidade de vida das idosas participantes do grupo. O domínio do próprio corpo e da rotina pessoal foram temas recorrentes nas discussões acerca da vivência de uma velhice saudável e prazerosa.

A partir da situação descrita, ressalta-se a importância de maiores e mais eficientes políticas públicas que criem melhores espaços para aqueles idosos que precisam estar em abrigos e asilos. Além disso, aponta-se a necessidade de melhores formações para os profissionais que atuem nessas instituições.

Apesar dos avanços, a velhice ainda foi descrita através de muitos termos negativos pelas idosas participantes da oficina, usualmente em contraste com períodos que eram considerados como momentos de maior vitalidade e oportunidades, como a infância, por exemplo. Para trabalhar a percepção negativa sobre a velhice, as idosas foram solicitadas a descreverem aspectos positivos e negativos da infância, juventude e velhice. 
A partir disso, foi possível marcar todas as fases da vida como momentos em que existem potencialidades e desafios. Tendo tal questão como foco, convidamos uma médica para falar sobre a parte biológica condizente ao envelhecimento; a partir disso, foram discutidas questões relacionadas à natureza multifatorial do envelhecimento, que aliado à trajetória de vida individual, gera múltiplas experiências de envelhecimento.

Após a apresentação das informações - em sua maioria não conhecidas pelas idosas -, foi discutida a importância da realização de exercícios físicos, do cuidado com a alimentação e constante acompanhamento médico, na perspectiva da promoção de saúde e não apenas da prevenção de doenças. Além disso, reforça-se a importância do acesso a informações pelas idosas, na tentativa de naturalizar o processo do envelhecimento, dissociando-o de uma perspectiva essencialmente negativa que só o relaciona a doenças. A partir das informações recebidas, é também possível reavaliar o próprio corpo na percepção pessoal dos limites e potencialidades, ou até mesmo na busca por tratamentos adequados aos sintomas "não-naturais" percebidos. Ademais, a troca entre as idosas, com a vivência de questões parecidas, permite a formação de uma rede de apoio que fortalece esses sujeitos nas dificuldades encontradas.

Nesse sentido, cabe relacionar a promoção da saúde com a autonomia do sujeito, visto que, de acordo com a Primeira Conferência Internacional de Promoção de Saúde organizada pela OMS em 1986, onde foi elaborada a Carta de Ottawa, trazida por Fleury-Teixeira et al. (2006), promover a saúde é capacitar os sujeitos para aumentar seu controle sobre sua vida, sendo a saúde entendida como um dos recursos necessários para uma vivência saudável no enfrentamento dos desafios cotidianos. Desse modo, a promoção da saúde enfatiza não apenas as capacidades físicas, mas também os recursos sociais e pessoais - nesse sentido, portanto, não sendo restrita à prática biomédica, mas se estendendo para outras áreas de atuação, como por exemplo, a Psicologia.

A falta de atendimento e acompanhamento psicológico, inclusive, leva a um grande desconhecimento acerca da prática desses profissionais e a um certo preconceito relacionado aos transtornos mentais.
As discussões apontaram uma grande recusa das idosas na busca por tratamentos psicológicos, por este ser usualmente associado ao uso de medicações, a transtornos mentais graves e para aqueles idosos que perdem a autonomia e a consciência de si.

A partir disso, reforça-se a necessidade da atuação consistente e informativa de psicólogos em locais voltados a presença de idosos. Apesar de uma certa rejeição com a Psicologia, por exemplo, o trabalho realizado na oficina aqui mencionada, realizada por estagiárias da área, foi bastante valorizado, apreciado e percebido como único espaço de escuta para muitas idosas. Desse modo, é importante continuamente desconstruir preconceitos relacionados à prática da Psicologia para que esta possa alcançar mais sujeitos e ocupar outros espaços.

\section{Considerações finais}

Ao longo do artigo, foi possível investigar o trabalho desenvolvido por alunas do curso de Psicologia nas "Oficinas Terapêuticas com Mulheres Velhas" e também analisar questões trazidas pelas participantes ao longo dos encontros, como o racismo, relações conjugais, autoestima e autoimagem e medos relacionados â velhice. Através da reflexão a cerca da experiência prática das oficinas, discutiu-se sobre o fenômeno do envelhecimento da mulher e suas particularidades.

Além disso, a experiência adquirida com a realização da "Oficina Terapêutica para Mulheres" foi possível verificar a importância de espaços como a UATI que, no contexto da oficina citada, se apresentou como um espaço empoderador e transformador. Dentre as mudanças sentidas pelas idosas ao longo dos encontros estão a descoberta de novas habilidades, a formação de novos vínculos entre as idosas e estagiárias e a construção de um espaço de acolhimento, onde temas que nunca foram conversados puderam ser discutidos. Todos esses pontos contribuem para uma velhice mais saudável em diversos níveis. Os fatores citados anteriormente tornaram a experiência na "Oficina Terapêutica para Mulheres" muito satisfatória, apesar da dificuldade inicial de captar pessoas e da falta de um espaço adequado para a realização de algumas atividades propostas, como as que envolviam atividades artísticas e/ou escritas. 
Destaca-se a importância de trabalhos que ajudem desconstrução da ideia negativa da velhice, considerando também os seus aspectos positivos e suas potencialidades. Além disso, enfatiza-se a importância de aprofundar a discussão e a troca estabelecida entre as participantes da oficina no que diz respeito a demandas trazidas pelas idosas que tocam em temas mais sensíveis, como as questões de gênero, raça e classe. Ademais, reforça-se a necessidade de uma prática contínua em Psicologia que considere o contexto onde o público-alvo está inserido, trabalhando dentro de uma perspectiva interseccional que considere as inúmeras vulnerabilidades existentes no nosso país.

\section{Contribuições dos autores}

Bernardo, K.J.C. participou da orientação, concepção, delineamento, análise, redação e revisão crítica do artigo científico. Barros, L. e Monteiro, K. participaram da concepção, delineamento, coleta e análise dos dados da pesquisa, interpretação dos resultados, e redação do artigo científico.

\section{Conflitos de interesses}

Nenhum conflito financeiro, legal ou político envolvendo terceiros (governo, empresas e fundações privadas, etc.) foi declarado para nenhum aspecto do trabalho submetido (incluindo, mas não se limitando a subvenções e financiamentos, participação em conselho consultivo, desenho de estudo, preparação de manuscrito, análise estatística, etc.).

\section{Referências}

Ministério da Saúde. (2004). Saúde mental no SUS: os Centros de Atenção Psicossocial. Secretaria de atenção à saúde. Departamento de Ações Programáticas Estratégicas. Ministério da Saúde. http://www.ccs.saude.gov.br/saude mental/pdf/sm_sus.pdf

Camarano, A. A., \& Kanso, S. (2010). As instituições de longa permanência para idosos no Brasil. Revista Brasileira de Estudos de População, 27(1), 232-235. https://doi. org/10.1590/S0102-30982010000100014

Campos, M. B., Borges, G. M., Queiroz, B. L., \& Santos, R. V. (2017). Diferenciais de mortalidade entre indígenas e não indígenas no Brasil com base no Censo Demográfico de 2010. Cadernos de Saúde Pública, 33(5), e00015017. https:// doi.org/10.1590/10.1590/0102-311x00015017
Daltro, M. R., Faria, A. A. (2019). Relato de experiência: Uma narrativa científica da pós-modernidade. Estudos \& Pesquisas em Psicologia, 19(1), 223-237. https://doi. org/10.12957/epp.2019.43015

Defensoria Pública do Estado da Bahia. (2015). Enfrentamento à violência doméstica [Cartilha]. Esdep. http://defensoria. ba.def.br/portal/arquivos/downloads/cartilha_ enfrentamento_a_violencia_domestica_SPREED2.pdf

Dornelas J. N., Nakamura, A. S., Cortez, L. E. R., \& Yamaguchi, M. U. (2015). Doenças sexualmente transmissíveis em idosos: uma revisão sistemática. Ciência \& Saúde Coletiva, 20(12), 3853-3864. https://dx.doi.org/10.1590/1413$\underline{812320152012.17602014}$

Duridan, A., Santos, D. F., \& Gatti, A. L. (2014). Autoestima e cuidados pessoais em mulheres de 60 a 75 anos. Aletheia, 43, 174-187. https://www.redalyc.org/ pdf/1150/115039411013.pdf

Estés, C. (1997). Mulheres que correm com os lobos. Rocco.

Fin, T. C. (2014). Velhice feminina e beleza corporal [Dissertação de mestrado, Universidade de Passo Fundo]. http://tede.upf. br/jspui/bitstream/tede/1147/1/2014ThaisCarolineFin.pdf

Fleury-Teixeira, P., Vaz, F. A. C., Campos, F. C. C., Álvares, J. Aguiar, R. A. T., \& Oliveira, V. A. (2008). Autonomia como categoria central no conceito de promoção de saúde. Ciência \& Saúde Coletiva, 13(Suppl. 2), 2115-2122. https://doi. org/10.1590/S1413-81232008000900016

Gonçalves, A. A. F. (2014). De oprimida e explorada a liberta e autônoma: o empoderamento feminino desvendado pelo universo da mulher longeva [Dissertação de Mestrado, Pontifícia Universidade Católica de São Paulo]. https:// tede2.pucsp.br/handle/handle/17066

Hooks, B. (2019). Teoria feminista: da margem ao centro. Perspectiva.

Jucá V. J. S., Medrado, A. C., Safira, L., Gomes, L. P. M., \& Nascimento, V. G. (2010). Atuação psicológica e dispositivos grupais nos centros de atenção psicossocial. Mental, 8(14), 93-113. http://pepsic.bvsalud.org/scielo. php?script=sci_arttext\&pid=S1679-44272010000100006

Lima, L. C. V., Bueno, C. M. L. B. (2009). Envelhecimento e gênero: a vulnerabilidade de idosas no Brasil. Revista Saúde e Pesquisa, 2(2), 273-280. https://periodicos.unicesumar.edu. br/index.php/saudpesq/article/view/1173/792

Martins, T. V., Lima, T. J. S., \& Santos, W. S. (2020). O efeito das microagressões raciais de gênero na saúde mental de mulheres negras. Ciência \& Saúde Coletiva, 25(7), 2793-2802. https://doi.org/10.1590/1413$\underline{81232020257.29182018}$ 
Menezes, L. (2018, 29 de setembro). População negra enfrenta desafios para garantir longevidade. Metrópoles. https:// www.metropoles.com/materias-especiais/populacaonegra-enfrenta-desafios-para-garantir-longevidade

Nunes, V. S., Torres, M. A., \& Zanotti, S. V. (2015). O psicólogo no caps: um estudo sobre oficinas terapêuticas. ECOS-Estudos Contemporâneos da Subjetividade, 5(2), 135-146. http:// www.periodicoshumanas.uff.br/ecos/article/view/1649/0

Pró-Reitoria de Extensão UNEB. (2013). Universidade aberta à $3^{a}$ idade. Núcleo Universidade Aberta à Terceira Idade. http:// www.nuati.uneb.br/

Oliveira, R. S. (2006). O significado do estar asilado para o idoso [Dissertação de Mestrado, Universidade Federal da Bahia]. Repositório Institucional UFBA. http://repositorio.ufba.br/ ri/handle/ri/10251

Penteado, S. R. L., Fonseca, A. M., Bagnoli, V. R., Assis, J. S., \& Pinotti, J. A. (2004). Avaliação da capacidade orgástica em mulheres na pós-menopausa. Revista da Associação Médica Brasileira, 50(4), 444-450. https://doi.org/10.1590/S010442302004000400038
Santos, N. M. C. (2016). Negras velhas: um estudo sobre seus saberes nas perspectivas de envelhecimento, trabalho, sexualidade e religiosidade [Dissertação de Mestrado, Universidade Federal do Rio Grande do Sul]. Lume Repositório Digital. https://lume.ufrgs.br/handle/10183/142030

Salgado, C. D. S. (2002). Mulher idosa: a feminização da velhice. Estudos interdisciplinares sobre o envelhecimento, 4, 7-19. https://seer.ufrgs.br/RevEnvelhecer/article/ view/4716/2642

Senado Federal. (2018). Panorama da violência contra as mulheres no Brasil [recurso eletrônico]: indicadores nacionais e estaduais. Observatório da Mulher contra a violência. http://www.senado.gov.br/institucional/datasenado/omv/ indicadores/relatorios/BR-2018.pdf

Silva, A., Rosa, T. E. C., Batista, L. E., Kalckmann, S., Louvison, M. C. P., Teixeira, D. S. C., \& Lebrão, M. L. (2018). Iniquidades raciais e envelhecimento:análise da coorte 2010 do Estudo Saúde, Bem-Estar e Envelhecimento (SABE). Revista Brasileira de Epidemiologia, 21(Suppl. 2), e180004. https:// doi.org/10.1590/1980-549720180004.supl.2

Yalom, I. D., Leszcz, M. (2006). Psicoterapia de grupo: teoria e prática. Artmed. 